\title{
CORRELATED COMPONENTS OF CHIASMA VARIATION AND THE CONTROL OF CHIASMA DISTRIBUTION IN RYE
}

\author{
G. H. JONES \\ Genetics Department, the University of Birmingham, England
}

Received 30.vii.73

\section{Summary}

The amounts of chiasma variation between and within pollen mother cells are correlated to a high degree over a wide range of rye genotypes. This correlation indicates that the variation between and within cells has an underlying common basis which has been identified as the error component of variance $\left(\sigma^{2}\right)$. It is concluded that the 30 rye genotypes studied differ among themselves primarily in the amount of error variation they show and hence in their degree of control over chiasma formation.

The amount of between-bivalent chiasma frequency variation is correlated with the pattern of chiasma positional distribution within bivalents. Increasing between-bivalent mean squares in the rye genotypes studied are accompanied by increasing proportions of non-distal chiasmata.

These correlations are considered in terms of one and two-component models of chiasma control. It is concluded that recombination is probably a two-step process in rye, as has been proposed for Dorsophila melanogaster, and that the rye distributional mutant lines are probably analogous to the so-called precondition mutants of Drosophila, that is they are defective in the establishment of exchange positions.

\section{Introduction}

THERE exists an abundant and increasing body of evidence for a complex genetic control of meiotic recombination in eukaryotes (Rees, 1961; Lindsley et al., 1967; Simchen and Stamberg, 1969). Efforts to analyse and dissect this control have largely involved the isolation and characterisation of gene mutations which alter recombination in various ways. The analysis of these mutants, whether studied genetically, or cytologically, has been largely concerned with the control of recombination frequency. Relatively little attention has been devoted to control over the distribution of recombination events. In genetical studies of recombination, this is largely unavoidable since breeding tests usually deal with limited portions of the genome. Cytological studies of chiasmata, on the other hand, are potentially much more informative in this respect since it is possible to specify not only the mean recombination frequency for the whole genome but also the pattern of chiasma (and hence cross-over) distribution through the genome. In fact, there is considerable evidence for a genetical component in the control of chiasma distribution, both directly (Rees and Thompson, 1958; Jones and Rees, 1964) and also by inference from the great variety of naturally occurring chiasma distribution patterns found among different plant and animal species. Even so, very few distributional mutants of major effect have been identified cytologically, although genetically determined changes in cross-over distribution have been invoked as possible explanations of the 
increased recombination frequencies sometimes observed by genetic means in partially desynaptic mutants (Rhoades and Dempsey, 1949; Miller, 1963; Moens, 1969).

An exceptional rye genotype was recovered (Jones and Rees, 1964; Jones, 1967) among the $\mathrm{F}_{2}$ segregants of an interspecific cross which showed every sign of being an extreme distributional mutant with a grossly altered pattern of chiasma distribution. During the ensuing analysis of this mutant, its pattern of chiasma distribution was compared with that found in wildtype rye at the three following levels of analysis: (i) between cells, (ii) between bivalents, within cells, (iii) within bivalents (Jones, 1967). It was found that while wild-type rye shows a very regular and even pattern of chiasma distribution, such that the different cells of an anther and the seven bivalents of each cell form very similar numbers of chiasmata, the distributional mutant possesses a very uneven and irregular distribution of chiasmata, resulting in a greatly increased range of cell and bivalent chiasma frequencies. Further analysis showed that the frequencies of various cell and bivalent chiasma frequency classes in the mutant agreed closely with expectations according to the Poisson distribution, suggesting that between-bivalent and between-cell chiasma distribution in this mutant is largely uncontrolled. Equally striking effects on chiasma distribution were also noted at the within-bivalent level. Wild-type rye normally possesses distally localised chiasmata, with each bivalent arm most frequently forming a single distal chiasma, although a second, non-distal, chiasma occasionally forms in the same arm. In the distributional mutant, by contrast, interstitial and proximal chiasmata form very frequently in addition to distal chiasmata. There is a change from the localised within-bivalent distribution typical of wild-type rye towards an unrestricted pattern with chiasmata forming in all bivalent regions. Previously (Jones, 1967) the changes in chiasma distribution at the between-cell, between-bivalent and within-bivalent levels were considered more or less independently as separate manifestations of a deranged control of chiasma distribution in this mutant. This present study emphasises the correlated changes in chiasma distribution at the three different levels of analysis and investigates the interrelationships of these variables in a wider range of rye genotypes. Models of chiasma control are discussed, based on these observations.

\section{Materials AND methods}

The rye genotypes used in this study were selected to show as wide and continuous as possible a range of chiasma distribution patterns. Altogether 40 genotypes were studied and these came from three quite different sources in order to cover as wide a range as possible and also to avoid the charge that the relationships described are a special property of an unrepresentative selection of genotypes. The sources of these rye genotypes were as follows:

1. 10 plants of a commercial winter rye variety, $R$ heidol $\left(R_{1}\right.$ to $\left.R_{10}\right)$.

2. 10 plants of a semi-inbred line of rye derived from a cross involving Secale vavilovii and an inbred line of $S$. cereale $\left(\mathrm{H}_{1}\right.$ to $\left.\mathrm{H}_{10}\right)$.

3. 20 plants belonging to an $\mathrm{F}_{2}$ family derived from a cross between the distributional mutant and wild-type rye $\left(J_{1}\right.$ to $\left.J_{20}\right)$. 
All observations were made on aceto-carmine stained squash preparations. Chiasma frequencies were scored from 50 randomly selected pollen mother cells per plant.

\section{Results}

(i) The interrelationship of between-cell and within-cell chiasma variation

The analysis of intra-individual chiasma variation is most conveniently handled by the analysis of variance (Mather, 1936). Applying this method to a sample of $p$ cells each with $n$ bivalents, the variation in chiasma frequency can be partitioned as follows:

Mean square $\quad \mathrm{N}$ (mean square is an estimate of:)

Between cells

$p-1$

$\sigma^{2}+n \sigma_{c}^{2}$

Between bivalents

$n-1$

Interaction (bivalents $\times$ cells) $(p-1)(n-1)$

$\sigma^{2} \quad+\sigma_{i}^{2}+p k_{b}^{2}$

$\sigma^{2}+\sigma_{i}^{2}$

The "expected mean square" column in the table shows what each calculated mean square actually estimates in terms of population parameters. $\quad \sigma_{c}^{2}$ represents that part of the variation ascribable solely to differences between cells, $k_{b}^{2}$ that ascribable to bivalent differences, where bivalents can be identified, $\sigma_{i}^{2}$ that ascribable to interactions of bivalents and cells, while $\sigma^{2}$ represents true error variation.

However, this complete analysis of variance is limited in application to situations where all bivalents of the complement are identifiable. More commonly, differences of chromosome size and morphology are insufficient to identify all bivalents, and this is the case in rye. In these circumstances, the complete analysis of variance is inappropriate and a modified, incomplete, analysis must be applied. The incomplete analysis partitions the chiasma variation into just two components, the between-cell mean square and the within-cell mean square, the latter being a compound of the betweenbivalent and interaction mean squares. The degrees of freedom and expected mean squares for this analysis are as follows:

Mean square

$$
\begin{array}{cc}
N & \text { Expected mean square } \\
p-1 & \sigma^{2}+n \sigma_{c}^{2} \\
p(n-1) & \sigma^{2}+\sigma_{i}^{2}+k_{b}^{2}
\end{array}
$$

Within cells

The first part of this study is concerned with the interrelationship of the between-cell and within-cell components of chiasma variation. Mather (1936) has reasoned that the nature of this relationship is central to our understanding of the control of chiasma variation within and between cells. The earlier analysis of chiasma conditions in the distributional rye mutant (Jones, 1967) revealed a correlated change in chiasma distribution at the between-cell and within-cell levels, and corresponding large increases, compared to wild-type rye, in the mean squares both between cells and within cells. This finding prompted the present, more extensive study of this relationship, based on data from a total of 30 diverse rye genotypes. Chiasma frequencies were scored in 50 randomly selected pollen mother cells from each plant and these data used to compute the between-cell and within-cell mean squares for each genotype (see table 1 and fig. 1). Inspection of fig. 1 shows evidence of a positive relationship between these 
TABLE 1

The chiasma frequency variation between the cells and bivalents of 30 rye genotypes belonging to three lines, expressed as the mean squares between cells (B.M.S.) and within cells (W.M.S.)

\begin{tabular}{|c|c|c|c|c|c|c|}
\hline \multirow[b]{2}{*}{ Plant no. } & \multicolumn{2}{|c|}{$\mathbf{R}$ line } & \multicolumn{2}{|c|}{$\mathrm{H}$ line } & \multicolumn{2}{|c|}{$J$ line } \\
\hline & B.M.S. & W.M.S. & B.M.S. & W.M.S. & B.M.S. & W.M.S. \\
\hline 1 & $0 \cdot 187$ & $0 \cdot 246$ & $0 \cdot 338$ & 0.494 & 0.539 & 0.671 \\
\hline 2 & 0.281 & 0.237 & 0.292 & 0.377 & 0.507 & 0.857 \\
\hline 3 & 0.080 & $0 \cdot 104$ & 0.305 & 0.410 & 0.701 & 0.801 \\
\hline 4 & 0.194 & 0.250 & 0.349 & 0.424 & 0.555 & 0.594 \\
\hline 5 & 0.253 & 0.309 & 0.311 & 0.405 & 0.567 & 0.823 \\
\hline 6 & $0 \cdot 153$ & 0.236 & 0.235 & 0.321 & 0.673 & 0.610 \\
\hline 7 & 0.063 & 0.073 & 0.254 & 0.384 & 0.387 & 0.563 \\
\hline 8 & $0 \cdot 107$ & $0 \cdot 115$ & 0.295 & 0.432 & 0.573 & 0.601 \\
\hline 9 & $0 \cdot 163$ & 0.233 & 0.346 & 0.496 & 0.455 & 0.582 \\
\hline 10 & 0.203 & 0.204 & 0.295 & 0.411 & 0.894 & $1 \cdot 164$ \\
\hline
\end{tabular}

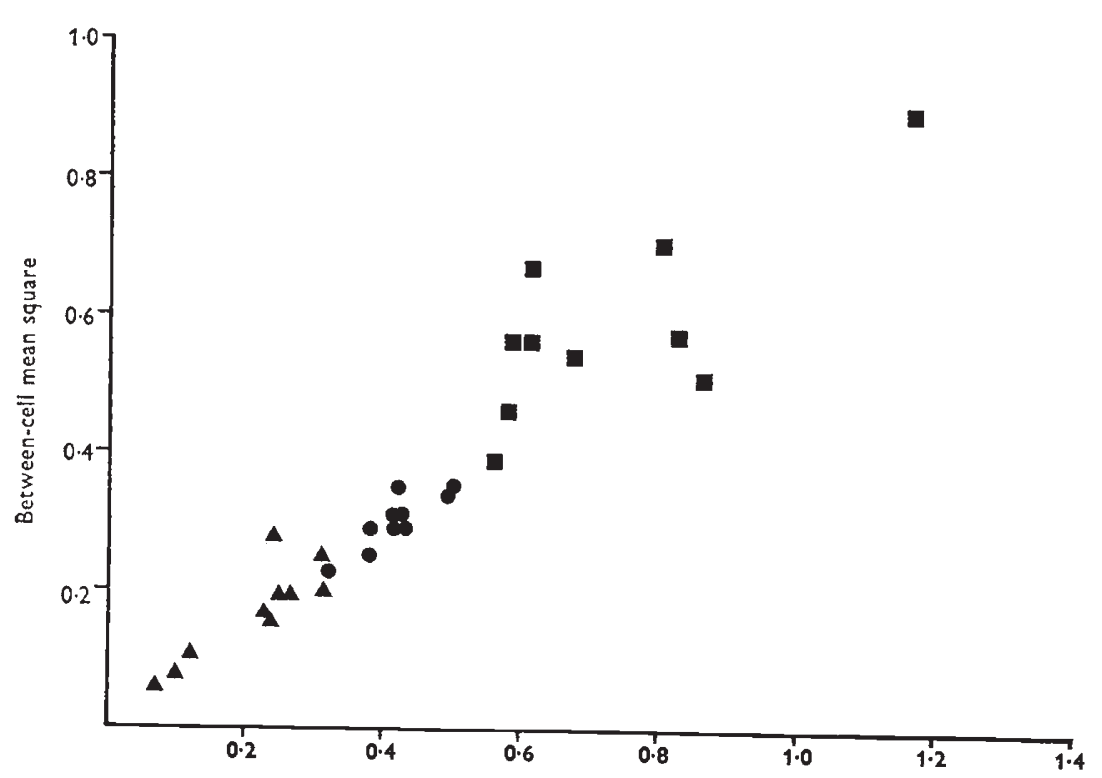

FIG. 1.-The mean squares for chiasma frequency variation between cells plotted against the mean squares for chiasma frequency variation within cells for 30 diverse rye genotypes. $(\boldsymbol{\Delta}=\mathrm{R}$ line; $\boldsymbol{\theta}=\mathrm{H}$ line; $\boldsymbol{\square}=\mathrm{J}$ line $)$.

variables. The distribution of chiasma variation seems to be related to the source of the material and for this reason correlation coefficients were first calculated for the $\mathrm{R}, \mathrm{H}$ and $\mathrm{J}$ lines, as follows:

$$
\begin{aligned}
& R \text { line: } r=0.862, t_{[8]}=4.816, \mathrm{P}<0.01 \\
& \text { H line: } r=0.844, t_{[8]}=4.442, \mathrm{P}<0.01 \\
& \mathrm{~J} \text { line: } r=0.748, t_{[8]}=3.183, \mathrm{P}<0.02
\end{aligned}
$$

The overall correlation is also, not surprisingly, highly significant $(r=0.946$, $\left.t_{[28]}=15.508, \mathrm{P}<0.001\right)$. The between-cell and within-cell mean squares calculated for these 30 rye genotypes are therefore correlated to a very high 
degree, and this correlation extends even to the variation within the three lines studied. The significance of this correlation is best assessed by a consideration of the between-cell and within-cell mean squares in terms of their expected mean squares, that is, in terms of the parameters which the calculated mean squares are estimating.

$$
\begin{aligned}
& \text { Between-cell mean square }=\sigma^{2}+n \sigma_{c}^{2} \\
& \text { Within-cell mean square }=\sigma^{2}+\sigma_{i}^{2}+k_{b}^{2} .
\end{aligned}
$$

It is apparent that the only component common to both mean squares is $\sigma^{2}$, the error component. It seems reasonable to deduce from this that the observed correlation of between- and within-cell mean squares is largely due to variation in $\sigma^{2}$. Otherwise, it must be proposed that $\sigma_{c}^{2}$ (which occurs in the between-cell mean square) is correlated with either $k_{b}^{2}$ or $\sigma_{t}^{2}$ (which

TABle 2

Components of chiasma frequency variation estimated from five different rye genotypes. The percentage

\begin{tabular}{|c|c|c|c|}
\hline \multirow[b]{2}{*}{ Genotype } & \multicolumn{3}{|c|}{ Components of variation } \\
\hline & $\sigma^{2}$ & $\sigma_{i}^{2}+k_{b}^{2}$ & $\sigma_{c}^{8}$ \\
\hline $\mathrm{J} 21$ & $\begin{array}{c}0 \cdot 4609 \pm 0 \cdot 1010 \\
(71 \%)\end{array}$ & $\begin{array}{c}0.1863 \pm 0.1100 \\
(29 \%)\end{array}$ & \\
\hline $\mathrm{J} 22$ & $\begin{array}{c}0.2796 \pm 0.0693 \\
(68 \%)\end{array}$ & $\begin{array}{c}0 \cdot 1198 \pm 0 \cdot 0742 \\
(29 \%)\end{array}$ & $\begin{array}{c}0.0137 \pm 0.0173 \\
(3 \%)\end{array}$ \\
\hline $\mathrm{J} 23$ & $\begin{array}{c}0.4531 \pm 0.1122 \\
(96 \%)\end{array}$ & $\begin{array}{c}0.0068 \pm 0.1153 \\
(1 \%)\end{array}$ & $\begin{array}{c}0.0136 \pm 0.0245 \\
(3 \%)\end{array}$ \\
\hline J 24 & $\begin{array}{c}0.4362 \pm 0 \cdot 1037 \\
(95 \%)\end{array}$ & $\begin{array}{c}0.0162 \pm 0.1077 \\
(4 \%)\end{array}$ & $\begin{array}{c}0.0048 \pm 0.0196 \\
(1 \%)\end{array}$ \\
\hline $\mathrm{J} 25$ & $\begin{array}{c}0.5006 \pm 0.0376 \\
(88 \%)\end{array}$ & & $\begin{array}{c}0.0649 \pm 0.0268 \\
(12 \%)\end{array}$ \\
\hline
\end{tabular}
of the total variation represented by each component is given in parentheses

occur in the within-cell mean square) or both, and since there are no a priori grounds to expect such correlations, the former explanation is more acceptable. Confirmation of the major contribution of the error component, $\sigma^{2}$, to intra-individual chiasma variation was obtained in a separate, more detailed, study of five rye genotypes which carried a cytological marker allowing the identification of one particular bivalent in all cells. The introduction of this extra statistic and a further statistic obtained by random sampling of one bivalent per cell from an independent sample of cells, made it possible to actually estimate some of the parameters involved by weighted least squares methods (table 2). It is clear from table 2 that $\boldsymbol{\sigma}^{2}$, the error component, is easily the most important component of chiasma variation in these five genotypes, accounting for between 68 and 96 per cent of the total variation according to genotype. On the whole $\sigma_{c}^{2}$ and $\left(\sigma_{i}^{2}+k_{b}^{2}\right)$ are small by comparison, and statistically non-significant, indicating that very little of the chiasma variation in rye can be attributed to genuine cell or bivalent effects or to identifiable interactions.

It seems very likely therefore that variation in the magnitude of $\sigma^{2}$ largely accounts for the wide variation in the amount of intra-individual chiasma variation over the 30 genotypes examined and that the contribution this component makes to both between-cell and within-cell mean squares accounts for the correlation of these mean squares. Since $\sigma^{2}$ is a measure of 
random or error variation in intra-individual chiasma variation, it appears that the 30 rye genotypes studied differ among themselves primarily in the amount of error variation they show and hence in the degree of control over chiasma formation.

An immediate practical consequence of the finding that mean squares between and within cells are correlated concerns the partitioning of the intraindividual variation into between-cell and within-cell components. Variation at these two levels evidently has a common basis, which has been identified as the error component, $\boldsymbol{\sigma}^{2}$. Furthermore, in the cases examined the other components of variation $\left(\sigma_{c}^{2}, \sigma_{i}^{2}, k_{b}^{2}\right)$ make relatively minor contributions to the total variation. Effectively, therefore, the between-cell and within-cell mean squares are both to a large extent estimates of $\sigma^{2}$ and consequently there remains little purpose to partitioning the intra-individual variation in this way. A better estimate of intra-individual chiasma variation is given by the total, unpartitioned, between-bivalent mean square. This mean square, in keeping with the finding that genuine cell effects are insignificantly small, ignores cell boundaries and regards the bivalents of a collection of pollen mother cells as belonging to a physiological continuum. This agrees with anatomical studies which show that the cytoplasm of adjacent pollen mother cells forms a physical continuum through intercellular bridges (Heslop-Harrison, 1964; Risueno et al., 1969; Whelan and Hornby, 1969).

\section{(ii) The interrelationship of between-bivalent and within-bivalent chiasma variation}

During the earlier study of the rye distributional mutant (Jones, 1967) it was noticed that the within-bivalent pattern of chiasma distribution was altered, in addition to changes at the between-cell and between-bivalent levels. Normally rye shows pronounced distal chiasma localisation so that chiasmata are confined to the ends of the metacentric and sub-metacentric bivalents, while in the distributional mutant many interstitial and even proximal chiasmata were seen (see fig. 9, Jones, 1967). It was decided to investigate this relationship further over a wider range of genotypes, and the material for this study was provided by $20 \mathrm{~J}$-line genotypes.

Bivalent chiasma frequencies and the within-bivalent positions of all chiasmata were recorded for 50 cells from each of the $20 \mathrm{~J}$-line genotypes. Chiasma frequency variation between bivalents was expressed as the total, unpartitioned, mean square of all the bivalent chiasma frequencies in each sample of 50 cells (between-bivalent mean square). Within-bivalent chiasma position was assessed by assigning each chiasma scored to one of three arbitrarily delimited regions (proximal, interstitial and distal) within each bivalent arm* and the pattern of within-bivalent chiasma distribution of each genotype was expressed, for the purpose of analysis, as the proportion of non-distal chiasmata (transformed to angles) scored in the sample of 50 cells. Fig. 2 shows the relationship of these variables when plotted against each other for the $20 \mathrm{~J}$-line genotypes. A correlation analysis con-

* As in most, if not all, plant species it is difficult to be more exact than this in defining within-bivalent chiasma distribution. This contrasts with the situations explored in some animal groups, notably among the Orthoptera, where the clarity of extended diplotene bivalents makes possible detailed measurements of the distances separating chiasmata and their relationships to the centromeres and telomeres (Henderson, 1963; Southern, 1967; Fox, 1973). 
TABLE 3

Chiasma distribution between and within the bivalents of $20 \mathrm{~F}$-line rye genotypes. Between-bivalent distribution is expressed as the bivalent mean square, while within-bivalent distribution is expressed as the proportion (transformed to angles) of non-distal chiasmata

\begin{tabular}{|c|c|c|c|c|c|c|}
\hline \multirow[b]{2}{*}{ Plant no. } & \multirow{2}{*}{$\begin{array}{l}\text { Between-bivalent } \\
\text { mean square }\end{array}$} & \multicolumn{3}{|c|}{ Chiasma positions within bivalents } & \multirow{2}{*}{$\begin{array}{l}\text { Proportion } \\
\text { non-distal } \\
\text { chiasmata }\end{array}$} & \multirow{2}{*}{$\begin{array}{c}\text { Proportion } \\
\text { non-distal } \\
\text { chiasmata } \\
\text { (angles) }\end{array}$} \\
\hline & & Proximal & Interstitial & Distal & & \\
\hline 1 & 0.337 & 1 & 33 & 543 & 0.059 & 14.06 \\
\hline 2 & 0.652 & 5 & 100 & 376 & 0.222 & $28 \cdot 11$ \\
\hline 3 & 0.361 & 0 & 74 & 486 & 0.132 & $21 \cdot 30$ \\
\hline 4 & 0.491 & 1 & 72 & 425 & 0.147 & $22 \cdot 54$ \\
\hline 5 & 0.432 & 1 & 87 & 492 & 0.152 & 22.95 \\
\hline 6 & 0.531 & 3 & 100 & 430 & 0.193 & 26.06 \\
\hline 7 & 0.304 & 0 & 46 & 536 & 0.079 & $16 \cdot 32$ \\
\hline 8 & 0.571 & 1 & 103 & 428 & 0.195 & $26 \cdot 21$ \\
\hline 9 & 0.468 & 5 & 97 & 469 & 0.179 & $25 \cdot 03$ \\
\hline 10 & 0.389 & 0 & 84 & 515 & $0 \cdot 140$ & 21.97 \\
\hline 11 & 0.652 & 21 & 166 & 274 & 0.406 & 39.58 \\
\hline 12 & 0.646 & 2 & 158 & 349 & 0.314 & 34.08 \\
\hline 13 & 0.788 & 6 & 190 & 358 & 0.354 & $36 \cdot 51$ \\
\hline 14 & 0.589 & 3 & 158 & 349 & 0.316 & $34 \cdot 20$ \\
\hline 15 & 0.787 & 22 & 148 & 305 & 0.358 & 36.75 \\
\hline 16 & 0.606 & 5 & 89 & 252 & 0.271 & 31.37 \\
\hline 17 & 0.538 & 0 & 166 & 451 & 0.269 & $31 \cdot 24$ \\
\hline 18 & 0.597 & 5 & 121 & 280 & 0.310 & 33.83 \\
\hline 19 & 0.564 & 2 & 158 & 349 & 0.314 & 34.08 \\
\hline 20 & $1 \cdot 124$ & 53 & 168 & 206 & 0.518 & $46 \cdot 03$ \\
\hline
\end{tabular}

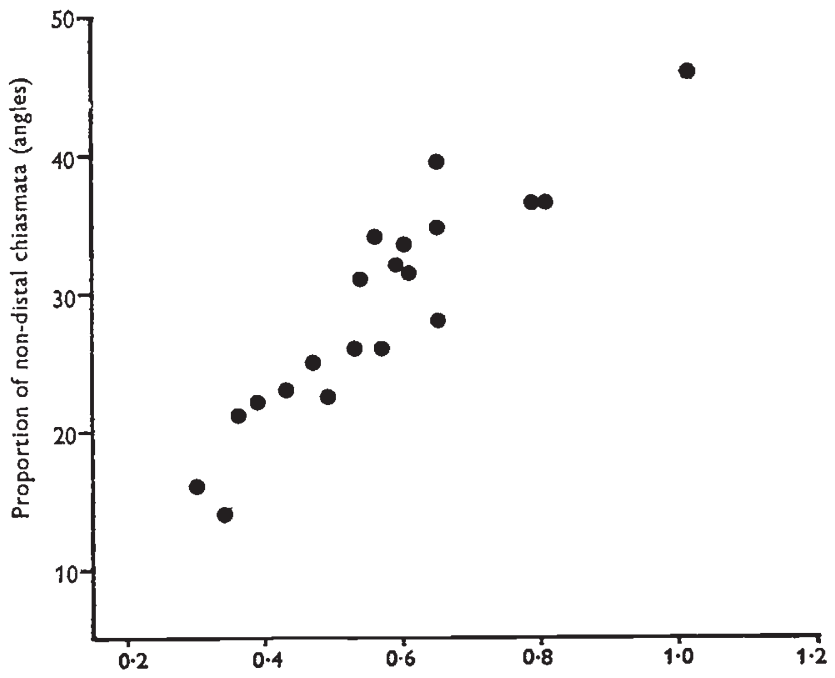

FIG. 2. - The proportion of non-distal chiasmata (transformed to angles) plotted against the total, unpartitioned, between-bivalent mean squares for $20 \mathrm{~J}$-line rye genotypes. This relationship demonstrates a connection between the chiasma frequency variation between bivalents and chiasma positional distribution within bivalents. 
firms a highly significant and positive correlation $\left(r=0.900, t_{[18]}=8.737\right.$, $\mathrm{P}<0.001$ ) of between-bivalent mean squares and within-bivalent chiasma distribution. Genotypes at the normal end of the range, having a regular pattern of between-bivalent chiasma distribution (reflected in a low betweenbivalent mean square), have most of their chiasmata localised distally and form very few interstitial and no proximal chiasmata. Increased betweenbivalent mean squares in other genotypes, interpreted earlier as symptomatic of reduced control and increased error variation, are accompanied by increased proportions of non-distal chiasmata. Most of these form interstitially but a good many proximal chiasmata are also formed, especially in the more disturbed genotypes. One obvious possible explanation of this relationship is that the incidence of non-distal chiasmata in these genotypes follows as an inevitable consequence of the altered betweenbivalent distribution. Increased between-bivalent mean squares mean that some bivalents have higher than normal chiasma frequencies and since all these chiasmata cannot form distally, some are bound to form in nondistal regions. However, this explanation can be shown to be inadequate since the probability of interstitial or proximal chiasma formation is not related to the chiasma frequency of the bivalents in which they occur. For example, monochiasmate bivalents in genotypes with relaxed control frequently form their single chiasmata in interstitial or even proximal locations. The increased frequency of non-distal chiasmata in these genotypes can therefore be regarded as an independent effect of some change in the controlling system governing chiasmata.

\section{Discussion}

Increased chiasma frequency variation between cells and within cells, and increased frequencies of non-distal chiasmata are all symptoms of relaxed control of chiasma distribution in rye. The correlated changes at these three levels of analysis, observed in a wide range of rye genotypes, suggest very strongly that all three aspects of chiasma variation are governed by a single controlling system.

Clear evidence has been presented that between-cell and within-cell chiasma frequency variation have a common basis and both are to a large extent simply measures of error variation $\left(\sigma^{2}\right)$, or the degree to which control is relaxed. A more surprising finding is the correlation of between-bivalent chiasma frequency variation and chiasma positional distribution within bivalents, since there is little, if any, previous suggestion that these two aspects of chiasma variation are connected in any way or that they are governed by a single control.

These correlations, though unexpected, are understandable in terms of a relatively simple model of chiasma control. According to this model, an uncontrolled situation can be envisaged as one in which each bivalent contains a very large number of potential sites* for chiasma formation, each site having a uniform but very low probability of chiasma formation and the sites being evenly disposed along the entire length of each bivalent. When these conditions obtain and the different bivalents of the complement

* The concept of recombination sites as specialised and discontinuously distributed regions of chromosomes where recombinational exchanges are initiated preferentially is supported by fungal recombination data (Whitehouse, 1966) and by observations on lampbrush chromosomes of amphibian oocytes (Callan, 1967). 
are equal, or nearly equal, in overall length, the between-bivalent distribution of chiasmata should be Poissonian as was actually found in the extreme distributional mutant of rye (Jones, 1967). These conditions should also lead to an unlocalised within-bivalent chiasma distribution pattern, with chiasmata forming with equal probability in all bivalent regions, and this was also approached if not exactly fulfilled in this mutant. The distribution pattern of chiasmata in this extreme mutant is therefore compatible with a total, or near total, absence of chiasma control which in turn is specifiable in terms of the site probability model outlined above. By the same token, the imposition of various degrees of control can similarly be interpreted within the framework of this model by postulating adjustments to site probabilities. Consider for example an hypothetical highly controlled situation in which two distal chiasmata (one in each arm) regularly form in each of the seven bivalents. In terms of the model, this would result if site probabilities were adjusted so that one distal site in each bivalent arm had a very high probability (approaching unity) of chiasma formation while all other sites in the bivalent were totally excluded from chiasma formation. This would achieve, in one step, regularity of between-bivalent chiasma distribution and also distal chiasma localisation within bivalents. There is, incidentally, good evidence for site-specific control of recombination frequency from studies on the genetic control of recombination within very short genetic intervals in the fungi Neurospora crassa (Jessop and Catcheside, 1965; Catcheside, 1966) and Schizophyllum commune (Simchen, 1967).

While this model is adequate to explain the observed correlation of between-bivalent and within-bivalent chiasma distribution, it must be regarded as a minimum model with several shortcomings, the most serious of which is its failure to take account of interference. For the same reason it is difficult to relate this model to the sequential models of chiasma control proposed by Mather (1937), Henderson (1963) and Fox (1973) which invoke chiasma interference as an important factor governing chiasma distribution. Unfortunately, no exact data on cross-over or chiasma interference is available for the rye plants studied and so a positive role for interference as an aspect of chiasma control in rye can only be inferred from its presumed presence in wild-type, controlled, genotypes and its presumed absence from the mutant line, based on the evidence of a Poissonian betweenbivalent chiasma distribution (Jones, 1967). The interference properties of the intermediate genotypes would also be interesting to study but again nothing is known of these at present. However, it is clear that the imposition of control according to the site-probability model outlined above will not automatically introduce interference since the model in its simplest form assumes that site probabilities are independent of one another. It is for this reason that the one-component model outlined above seems inadequate to explain all the observed and inferred recombinational properties of the rye genotypes under study.

A two-component model of cross-over control has been proposed by Sandler et al. (1968) and although this model is based on genetical observations of meiotic mutants of Drosophila melanogaster it is nevertheless instructive to consider the situation found in the mutant lines of rye, based as it is on cytological observation, in terms of this model. This model is based on the observation that certain meiotic mutants of Drosophila show altered 
coincidence values while others do not and proposes that the formation of recombinants should be viewed as a two-step process consisting of the establishment of exchange points (exchange pre-conditions) followed by exchange itself. On theoretical grounds it has been proposed that mutants affecting these two steps should produce very different effects on recombination (Sandler et al., 1968). It was argued that defects in the first step, the establishment of exchange points, should produce altered coincidence values while simply altering the probability of exchange should leave coincidence values unchanged. More recently (Carpenter and Sandler, in press), it has been proposed that the uniformity or non-uniformity of the decrease in exchange in recombination deficient mutants is a more reliable indicator of whether any particular mutant is involved in precondition defects or defects in exchange itself. Mutants affecting the distribution of sites for exchange (precondition mutants) are thought to cause a non-uniform reduction in recombination along the chromosome while mutants which simply alter exchange probabilities result in a uniform reduction in recombination.

Based on the above criteria, the rye distributional mutant lines resemble remarkably closely the so-called precondition mutants of Drosophila. The altered pattern of within-bivalent chiasma distribution seen in the rye mutant, from the strictly distally localised pattern of wild-type rye to an unlocalised, distributed, pattern is analogous to the non-uniform, polar, reduction in cross-over frequency shown by the Drosophila preconditional mutants. Indeed, Baker and Carpenter (1972) from an analysis of several Drosophila meiotic mutants have concluded that the effect of precondition mutants might be to relax constraints on the spatial distribution of sites for exchange, thus producing a genetic map which is much more like the physical map than is found in wild-type. This conclusion is remarkably similar to that reached independently from observations on the rye distributional mutant (Jones, 1967 and present report). Furthermore, the Drosophila precondition mutants show reduced coincidence values which is an analogous situation to the inferred reduction, or absence, of chiasma interference in the rye mutant (based on a Poissonian between-bivalent chiasma distribution). These similarities argue, therefore, that the rye distributional mutant may in fact be defective in the establishment of exchange positions (i.e. a precondition mutant) and that consequently recombination may be a two-step process in rye, as has been proposed for Drosophila.

In terms of this two-component model, we can imagine that wild-type rye has only a few potential sites for exchange, localised in distal regions of bivalents. The probabilities of satisfying the exchange preconditions at these sites are uniformly high, resulting in a localised and strictly regular distribution of actual exchange sites and hence of chiasmata both between and within bivalents. In the distributional mutant of rye, on the other hand, we can suppose that there are many potential sites for exchange evenly distributed throughout the genome, each with a low but uniform probability of satisfying the exchange preconditions. The actual exchange sites specified by these conditions should be distributed in an independent manner both between and within bivalents leading to statistically random distribution patterns, and the distribution patterns of chiasmata actually observed in the rye mutant are reassuringly similar to those predicted (Jones, 1967). The actual probability of exchange in the mutant is of course the same as in 
wild-type rye. The inferred variable interference properties of these rye genotypes is explained by assuming that certain interactions occur during the establishment of exchange positions in wild-type rye, which are absent from the mutant.

A further noteworthy feature of the chiasma data presented here is the extension of the corrleated changes in chiasma distribution through a more or less continuous range of intermediate genotypes between the extremes of wild-type and extreme mutant forms. Since the wild-type and mutant genotypes are thought to represent conditions of full control and no control respectively, with respect to the determination of exchange site distribution, it is suggested that the intermediate genotypes possess varying degrees of control over exchange site distribution and therefore show varying amounts of error chiasma variation (defined earlier as $\sigma^{2}$ ). The continuous nature of the variation in chiasma distribution among these genotypes indicates that it is under a complex genetic control which is capable of fine adjustment.

TABLE 4

Chiasma distribution within and between the bivalents of two clones of Trillium kamtschaticum

\begin{tabular}{|c|c|c|c|c|c|c|c|c|c|}
\hline \multirow[b]{2}{*}{ Clone 1} & \multicolumn{5}{|c|}{ Chiasmata per bivalent } & \multirow[b]{2}{*}{$\begin{array}{l}\text { Between-bivalent } \\
\text { mean square } \\
0 \cdot 161\end{array}$} & \multicolumn{3}{|c|}{ Chiasma positions within bivalents } \\
\hline & $\begin{array}{l}0 \\
3\end{array}$ & $\begin{array}{c}1 \\
26\end{array}$ & $\begin{array}{c}2 \\
216 \\
(86 \cdot 4 \%)\end{array}$ & $\begin{array}{l}3 \\
5\end{array}$ & $\begin{array}{l}4 \\
0\end{array}$ & & $\begin{array}{c}\text { Proximal } \\
466 \\
(98 \cdot 5 \%)\end{array}$ & $\begin{array}{c}\text { Interstitial } \\
5\end{array}$ & $\begin{array}{c}\text { Distal } \\
2\end{array}$ \\
\hline Clone 2 & 7 & 54 & $\begin{array}{c}163 \\
(65 \cdot 2 \%)\end{array}$ & 24 & 2 & $0 \cdot 432$ & $\begin{array}{c}407 \\
(88.5 \%)\end{array}$ & 33 (11 & 20 \\
\hline
\end{tabular}

No attempt has been made so far to identify the exchange preconditions which must be satisfied before exchange can be initiated at a site according to the two-component model. In the case of rye one obvious possibility, the completeness of homologous pairing, can be eliminated since pairing is visibly complete in both wild-type and mutant rye, despite the difference shown by them in the distribution of exchange sites.

The critical observations underlying the models of chiasma control discussed here concern the correlated changes in chiasma distribution at the between-bivalent and within-bivalent levels. As a prelude to discussing the wider implications of these models, it is pertinent to enquire first whether similar relationships are found in other species or whether this correlation is unique to rye. Some chance observations of meiosis in an unrelated plant species do in fact provide a further example of this correlation. Trillium kamtschaticum $(2 n=10)$ normally shows pronounced chiasma localisation of the proximal type, with chiasmata forming only in proximal, centromeric, regions within each of the five bivalents (Dyer, 1964). Two clones of this species were available for study which, by good fortune, differed somewhat in their chiasma distribution patterns (see table 4).

Clone 1 shows a very regular pattern of chiasma distribution. In a sample of 50 cells, nearly all bivalents $(86.4$ per cent) form two chiasmata with only occasional instances of three, one or no chiasmata. The overall picture is therefore one of great regularity and this is reflected in a low between-bivalent mean square $(0 \cdot 161)$. Correlated with this great regularity at the between-bivalent level is a striking degree of proximal chiasma localisa- 
tion. Only 1.5 per cent of all chiasmata recorded in a sample of 50 cells formed in non-proximal regions.

Glone 2 shows a less regular and therefore less controlled pattern of chiasma distribution. The important point to note, however, is that this relaxed control is reflected in correlated changes at the between-bivalent and within-bivalent levels. At the between-bivalent level there is markedly more variation in bivalent chiasma frequencies (see table 4) compared to clone 1 and this is reflected in a much higher between-bivalent mean square $(0 \cdot 432)$. At the within-bivalent level there is, if anything, a more dramatic change; the percentage of non-proximal chiasmata increases from 1.5 per cent (Clone 1) to 11.5 per cent. Therefore, although only two clones of Trillium kamtschaticum were compared, there is a clear correlation of betweenbivalent and within-bivalent chiasma distribution in this material and this correlation is qualitatively identical to that described in the larger sample of rye genotypes.

The discovery of a similar system of chiasma variation in Trillium kamtschaticum to that already described in rye indicates that the model of chiasma control discussed above may have a more general validity. The detection of this special system of chiasma variation in rye and Trillium kamtschaticum is attributed to the fact that both species normally possess localised and very regular patterns of chiasma distribution against which any alterations to the pattern of chiasma distribution are immediately obvious. The possession by two quite unrelated species of such similar systems of chiasma variation and control together with the evident analogies between the meiotic mutants of rye and Drosophila argue that these systems may prove to be widespread among eukaryotes.

Acknowledgments.-I am indebted to Dr M. J. Kearsey and Dr J.S. Gale for many helpful discussions, especially concerning the interpretation of statistical findings. Dr M. J. Kearsey also carried out the least square estimations of mean square components given in table 2. Professor K. Mather read the manuscript and made many useful suggestions. I am also grateful to Dr L. Sandler for his comments on the manuscript.

\section{REFERENGES}

BAKER, B.S., AND CARPENTER, A. T. C. 1972. Genetic analysis of sex chromosomal meiotic mutants in Drosophila melanogaster. Genetics, 71, 255-268.

CAllan, H. G. 1967. On the organisation of genetic units in chromosomes. 7. Cell Sci., 2, 1-7.

CARPENTER, A. T. C., AND SANDLER, L. On recombination-defective mutants in Drosophila melanogaster. Genetics, in press.

CATChEside, D. G. 1966. A second gene controlling allelic recombination in Neurospora crassa. Aust. 7. Biol. Sci., 19, 1039-1046.

DYER, A. F. 1964. Heterochromatin in American and Japanese species of Trillium. III. Chiasma frequency and distribution and the effect on it of heterochromatin. Cytologia, 29, 263-279.

Fox, D. P. 1973. The control of chiasma distribution in the locust, Schistocerca gregaria (Forskảl). Chromosoma, Berl., 43, 289-328

HALDANE, J. B. s. 1931. The cytological basis of genetical interference. Cytologia, 3, 54-65. HENDERSON, S. A. 1963. Chiasma distribution at diplotene in a locust (Schistocerca gregaria). Heredity, 18, 173-190.

HESLOP-HARRISON, J. 1964. Cell walls, cell membranes and protoplasmic connections during meiosis and pollen development. In Pollen Physiology and Fertilization, Ed. J. F. Linkskens. North Holland, Amsterdam. 
JESSOP, A. P., AND CATCHESIDE, D. G. 1965. Interallelic recombination at the his-l locus in Neurospora crassa and its genetical control. Heredity, 20, 237-256.

JoNes, G. H. 1967. The control of chiasma distribution in rye. Chromosoma, Berl., 22, 69-90. JONES, G. H., AND REES, H. 1964. Genotypic control of chromosome behaviour in rye. VIII. The distribution of chiasmata within pollen mother cells. Heredity, 19, 719-730. LINDSLEY, D. L., SANDLER, L., NICOLETTI, B., AND TRIPPA, G. 1967. The genetic control of recombination in Drosophila. In Replication and Recombination of Genetic Material, Ed. W. J. Peacock and R. D. Brock. Australian Academy of Science, Canberra.

Mather, K. 1936. Competition between bivalents during chiasma formation. Proc. roy. Soc. $(B), 120,208-227$.

MATHER, K. 1937. The determination of position in crossing-over. II. The chromosome length-chiasma frequency relation. Cytologia, Fujii Jub. vol., 514-526.

MiLleR, O. L. 1963. Cytological studies in asynaptic maize. Genetics, 48, 1445-1466.

MOENS, Р. в. 1969. Genetic and cytological effects of three desynaptic genes in the tomato. Canad. F. Genet. Cytol., 11, 857-869.

REES, H. 1961. Genotypic control of chromosome form and behaviour. Bot. Rev., 27, 288318.

REES, H., AND THOMPSON, J. B. 1958. Genotypic control of chromosome behaviour in rye. V. The distribution pattern of chiasmata between pollen mother cells. Heredity, 12, $101-111$.

RHOADES, M. M., AND DEMPSEY, E. 1949. Maize Genet. Coop. News Letter, 23, 56-57.

RISUEÑo, M. C., GMÉNEZZ-MARTÍ, G., LóPEZ-SÁEZ, J. P., AND R.-GARCIA, M. I. 1969. Connexions between meiocytes in plants. Cytologia, 34, 262-272.

SANDLER, L., LINDSLEY, D. L., NICOLETTI, B., AND TRIPPA, G. 1968. Mutants affecting meiosis in natural populations of Drosophila melanogaster. Genetics, 60, 525-558.

simcheN, G. 1967. Genetic control of recombination and the incompatibility system in Schizophyllum commune. Genet. Res. Camb., 9, 195-210.

STMCHEN, G., AND STAMBERG, J. 1969. Fine and coarse controls of genetic recombination. Nature, 222, 329-332.

southern, D. I. 1967. Chiasma distribution in truxaline grasshoppers. Chromosoma, Berl., $22,164-191$.

WHELAN, E. D. P., AND HORNBY, C. A. 1969. Meiotic synchrony, cytoplasmic continuity and cytomictic phenomena during microsporogenesis of Prunus avium. Can. F. Genet. Cytol., $11,668-672$.

WHITEHOUSE, H. L. K. 1966. An operator model of crossing-over. Nature, 211, 708-713. 